\title{
BOUNDEDNESS FOR THE MULTI-COMMUTATORS OF CALDERÓN-ZYGMUND OPERATORS
}

\author{
XIANGXING TAO AND YUNPIN WU
}

Abstract. In this paper, the authors study the multi-commutators $\mathscr{T}^{A_{1}, \cdots, A_{k}}$ generalized by the Calderón-Zygmund operator $T$ and the $\left(m_{i}+1\right)$-th remainders of Taylor series of the functions $A_{i}$ whose $m_{i}$-th derivatives belong to $B M O$ spaces for $m_{i} \geqslant 0$ and $i=1,2, \cdots, k$. The boundedness from the weighted central Morrey space $B_{p}(w)$ to the weighted central $B M O$ space $C M O(w)$ for these multi-commutators was derived. As corollary, the $L^{p}$-boundedness for the multi-commutators has been obtained.

Mathematics subject classification (2010): 42B20, 42B25, 42B30.

Keywords and phrases: Multi-commutator, Calderón-Zygmund operator, $C M O(w)$ space, $B_{p}(w)$ space, $L^{p}$-boundedness.

\section{REFERENCES}

[1] A. Beurling, Construction and analysis of some convolution algebras, Ann. Inst. Fourier Grenoble 14 (1964), 1-32.

[2] R. Coifman, R. Rochberg And G. Weiss, Factorization theorems for Hardy spaces in several variables, Annals of Mathematics 103 (1976), 611-635.

[3] J. COHEN AND J. Gosselin, A BMO estimate for multilinear singular integral operators, Illinois J. Math. 30 (1986) 3, 445-465.

[4] S. Hofmann, On some nonstandard Calderón-Zygmund operators, Studia Math. 109 (1994) 2, 105131.

[5] S.-Z. LU AND D.-Y. YAN, $L^{p}$ boundedness of multilinear oscillatory singular integrals with CalderónZygmund kernel, Science in China (Ser. A) 45 (2002) 2, 196-213.

[6] C. PÉRZE AND R. TRUjILlo-GonzÁLEZ, Sharp weighted estimates for multilinear commutators, J. London Math. Soc. 65(2002), 672-692.

[7] X.-X. TAO AND Y.-L. SHI, Multilinear Commutators of Calderón-Zygmund operator on $\lambda$-central Morrey spaces, Advance in Math. (China) 40 (2011) 1, 47-59.

[8] X.-X. TAO AND T.-T. ZHENG, Multilinear commutators of fractional integrals over Morrey spaces with non-doubling measures, Nonlinear differential equations and applications 18 (2011) 3, 287-308. 